\title{
Next Generation Experiments and Models for Shock Initiation and Detonation of Solid Explosives
}

\author{
Craig M. Tarver
}

This paper was prepared for submittal to the

11 th APS Topical Conference on Shock Compression

of Condensed Matter

Snowbird, UT

June 27-July 2, 1999

June 1999

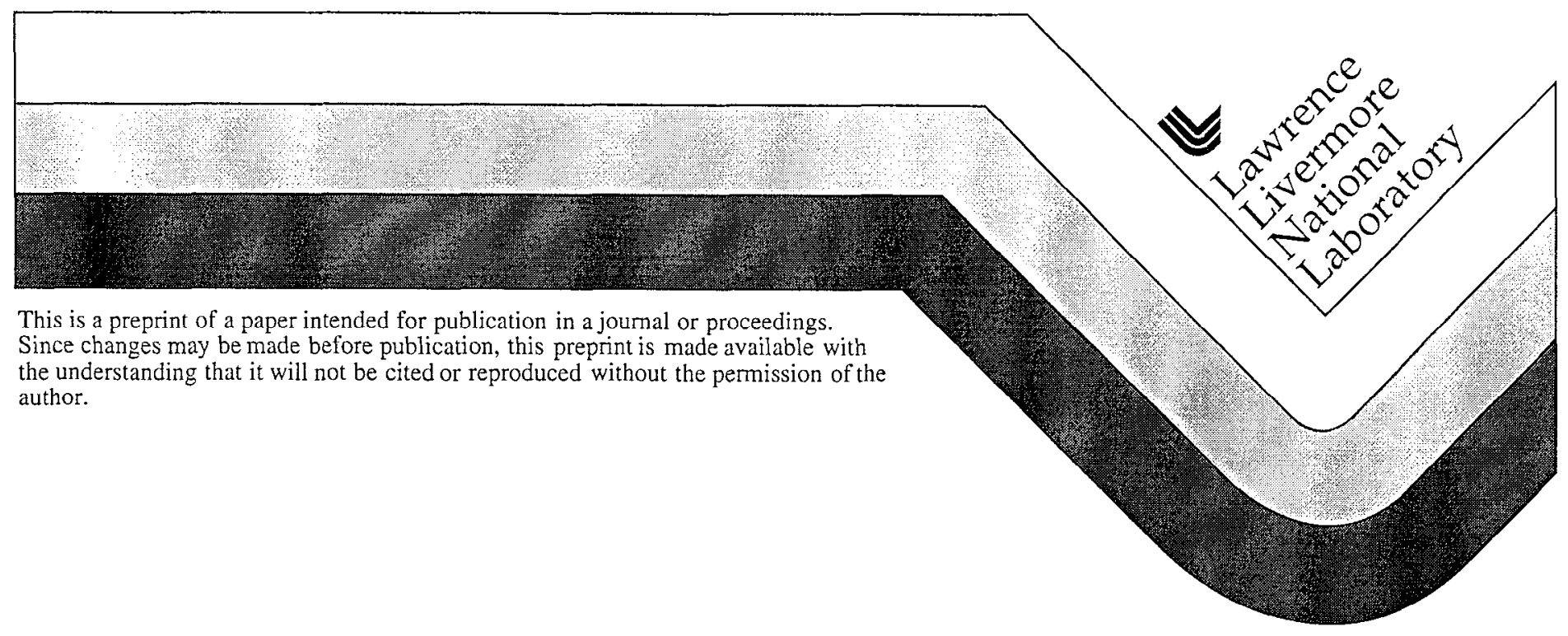




\section{DISCLAIMER}

This document was prepared as an account of work sponsored by an agency of the United States Government. Neither the United States Government nor the University of California nor any of their employees, makes any warranty, express or implied, or assumes any legal liability or responsibility for the accuracy, completeness, or usefulness of any information, apparatus, product, or process disclosed, or represents that its use would not infringe privately owned rights. Reference herein to any specific commercial product, process, or service by trade name, trademark, manufacturer, or otherwise, does not necessarily constitute or imply its endorsement, recommendation, or favoring by the United States Government or the University of California. The views and opinions of authors expressed herein do not necessarily state or reflect those of the United States Government or the University of California, and shall not be used for advertising or product endorsement purposes.

This report has been reproduced directly from the best available copy.

Available to DOE and DOE contractors from the Office of Scientific and Technical Information

P.O. Box 62, Oak Ridge, TN 37831

Prices available from (615) 576-8401, FTS 626-8401

Available to the public from the

National Technical Information Service

U.S. Department of Commerce

5285 Port Royal Rd.,

Springfield, VA 22161 


\title{
NEXT GENERATION EXPERIMENTS AND MODELS FOR SHOCK INITIATION AND DETONATION OF SOLID EXPLOSIVES
}

\author{
Craig M. Tarver \\ Lawrence Livermore National Laboratory \\ P.O. Box 808, L-125, Livermore, CA 94551
}

Current phenomenological hydrodynamic reactive flow models, such as Ignition and Growth and JohnsonTang-Forest, when normalized to embedded gauge and laser velocimetry data, have been very successful in predicting shock initiation and detonation properties of solid explosives in most scenarios. However, since these models use reaction rates based on the compression and pressure of the reacting mixture, they can not easily model situations in which the local temperature, which controls the local reaction rate, changes differently from the local pressure. With the advent of larger, faster, parallel computers, microscopic modeling of the hot spot formation processes and Arrhenius chemical kinetic reaction rates that dominate shock initiation and detonation can now be attempted. Such a modeling effort can not be successful without nanosecond or better time resolved experimental data on these processes. The experimental and modeling approaches required to build the next generation of physically realistic reactive flow models are discussed.

\section{INTRODUCTION}

Phenomenological hydrodynamic reactive flow models, such as Ignition and Growth (1) and Johnson-Tang-Forest (2), have been very successful in predicting shock initiation and detonation in solid explosives. These models use compression and pressure of the reacting mixture in their reaction rate equations. The main experimental tools available to study shock initiation and detonation have been embedded manganin pressure gauges (3), embedded particle velocity gauges (4), and various applications of laser velocimetry, such as Fabry-Perot (5) and VISAR (6). Thus, when normalized to the measured pressure and/or velocity versus time data, the pressure and compression dependent reaction rates have been able to predict shock initiation and detonation wave propagation in one, two and three dimensions for most initial conditions in most applications. Of course, the modeling, especially in 3D, was limited by the size and speed of the available computers. With the advent of teraflop, parallel computers, these size and speed limitations have largely disappeared. The Ignition and Growth and Johnson-Tang-Forest reactive flow models are now being used on the large parallel machines.
However, it has long been known that shock initiation of solid explosives is controlled by local reaction sites called "hot spots" (7) and that detonation waves have complex, 3D structures containing many Mach stem interactions (8). To model more exactly the physical and chemical processes that control reactions in solid explosives, the next generation of reactive flow model is required. The new generation of computers certainly allows such microscopic models to be built and tested in a timely manner. To really benefit from these models, the next generation of experimental tools with improved spatial and time resolutions must also be developed. This paper discusses some of the properties that are desired in the next generation of microscopic reactive flow models and the associated experimental techniques.

\section{NEW REACTIVE FLOW MODELS}

Chemical reaction rates are always governed by the local temperature of the reacting material. Therefore, the local reaction rates in the heated regions which either ignite and form growing "hot spots" or fail to ignite due to conductive heat losses are intimately coupled to the physical mechanisms that create such 
heated regions. The next generation reactive flow models must accurately describe the physical processes (void collapse, friction, shear, viscosity, etc.) that form hot spots and the states (temperature, dimensions, geometry, pressure, etc.) that these hot spots attain. Various hot spot formation models have been proposed (9), and a statistical hot spot formation and reaction growth model was developed in a one-dimensional hydrodynamic code (10). The Ignition and Growth model was written using the temperature dependent form of the Jones-Wilkins-Lee (JWL) equation of state, and temperature dependent Arrhenius reaction rates were used for liquid explosives, for which temperature data exists (11).

The usefulness of such modeling has been limited by both experimental and computational factors. The main experimental limitation is the lack of local time resolved temperature measurements. This and other experimental requirements are discussed in the next section. The main computational obstacle was the lack of coupling of thermal- mechanical codes to hydrodynamic codes. This obstacle has recently been overcome in the ALE3D, LS-DYNA2D/3D, and other hydrodynamic codes. This coupling has allowed modelers to study the hydrodynamic formation of hot spots using various dissipation mechanisms and heat transfer to the surrounding cooler material in $3 \mathrm{D}$ mesoscale meshes containing over one billion computational explosives using elements (12).

Critical conditions for the subsequent growth or failure of the heated regions for HMX-and TATB-

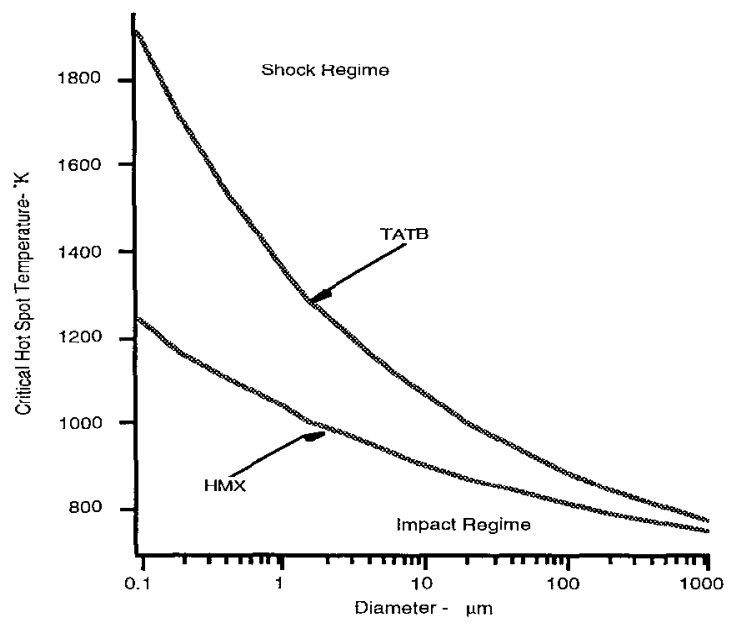

Figure 1. Critical spherical hot spot temperatures in HMX and TATB at various diameters based explosives have been calculated using their multistep Arrhenius kinetic chemical decomposition models derived from thermal explosion and kinetic experiments (13). Figure 1 shows the calculated critical hot spots temperatures in HMX and TATB for spheres of various geometries. The growth rates of the reacting hot spots into the surrounding shocked solid explosive particles and the interactions of several growing hot spots have been calculated for various geometries (14). Figure 2 shows the times required for spherical HMX particles of various radii to complete deflagrate inwardly under various boundary temperature conditions. These calculations are the beginning stages of an all-Arrhenius microscopic model, but the development of a complete predictive model requires much more work.

The hot spot growth rate solely by heat conduction study (14) showed that in the high pressure, high temperature larger explosive particles must fragment, producing smaller, less regular particles with a grcat deal more reactive surface area for the hot gaseous reaction products to ignite. This is one of the two major areas of study currently in progress during the development of an fully coupled thermal-chemicalmechanical reactive flow model. The other major research area is the equation of state of both the unreacted explosive and its reaction products. Since local temperatures are now being used to control the reaction rates, they must be calculated much more accurately than in previous models. For example, for the unreacted explosive, the Ignition and Growth model uses a simple elastic-plastic solid model with

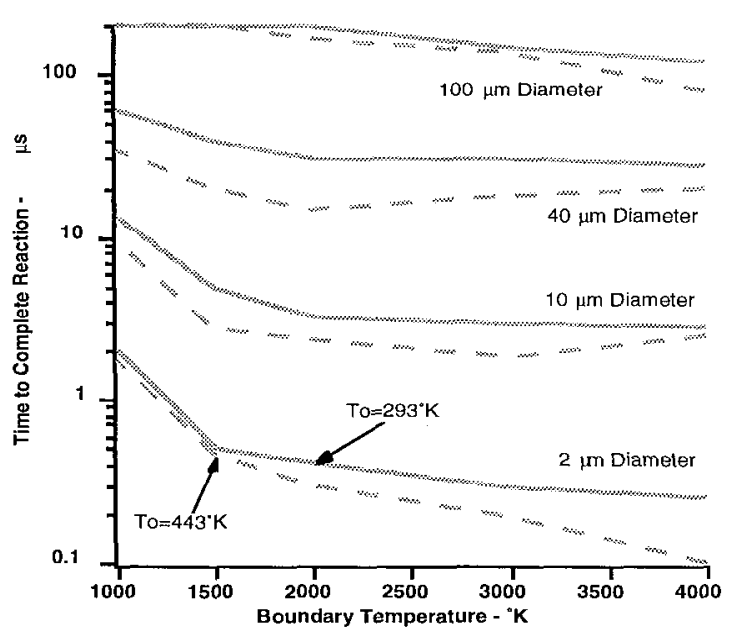

Figure 2. Reaction times for spherical HMX particles 
a constant shear modulus and yield strength together with a temperature dependent JWL equation of state with a constant Gruneisen paraneter and a constant heat capacity. This material model is then fit to the usual hydrodynamic data for the unreacted Hugoniot curve. Particularly for impact and weak shock compression scenarios, the mechanical portion of the unreacted explosive equation of state must be more physically based and normalized to strain rate dependent experimental data. The thermal energy term of the equation of state must contain all experimentally observed dependencies, such as the Gruneisen coefficient on the specific volume, the heat capacity on the temperature, phase transitions, etc. Similarly, for the reaction product equation of state, the temperature of the products must be calculated as correctly as possible, because the heat transfer from these products to the surrounding cooler unreacted explosive drives the decomposition rates. Recent advances in the product equation of state predictions by thermochemical codes, such as CHEETAH (15) and CHEQ (16), will be helpful in determining the correct relative importance of cold compression and thermal energies in these products.

Once all of these improvements are addod to the material models in hydrodynamic codes with fully coupled thermal-chemical-mechanical properties, the next generation of reactive flow models will be ready for testing. Whether they advance far beyond the current generation of reactive flow models depends on the development of new advanced experimental techniques. The ultimate goal is to develop models that describe all of the physical and chemical proccsses that occur in reactive flows. For example, in the case of steady state detonation, Figure 3 illustrates the 3D non-equilibrium processes that precede and follow chemical reaction (14). In the much less extreme environments of gas phase detonation waves, most of the processes are being identified, measured experimently in shock tubes, and are being modeled quite accurately in one and two dimensions, at least in systems with relatively simple chemical kinetic mechanisms, such as $\mathrm{H}_{2}+$ $\mathrm{Cl}_{2}, \mathrm{H}_{2}+\mathrm{O}_{2}$, and ozone (17). Extension to 3D gas phase calculations on large parallel machines is progressing. Modeling 2D detonations in homogeneous liquid explosives has also begun (18). In liquid and solid explosives, measurements of the multiphonon up-pumping and intramolecular vibrational energy redistribution (IVR) processes are being made (19). Carbon condensation and the equilibrium C-J state is another area of current study.

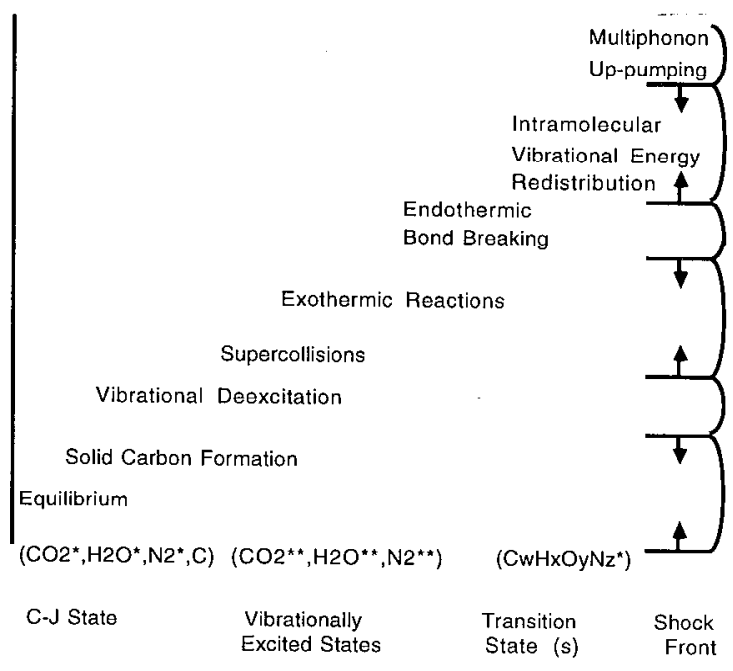

FIGURE 3. The non-equilibrium Zeldovich - von Neumann-Doring (ZND) model of detonation

\section{NEW EXPERIMENTAL TECHNIQUES}

Eventually reactive flow modeling of solid explosives should include the rates of disappearance of the unreacted material, the appearance and subsequent disappearance of intermediate products, and the appearance of the final stable reaction products. The external excitation of all these species also determine the individual reaction rates. Some of this information is known for gaseous systems, and some preliminary spectroscopy in shocked liquid explosives is being done (20). For the foreseeable future, the most important experimental data required for advanced impact ignition and shock initiation modeling purposes is spatial and time resolved temperatures of hot spots and the surrounding unreacted explosive particles. Brightness techniques have yielded nanosecond resolution temperature measurements for transparent liquids and solid crystals under shock and detonation conditions (21). Fast time response thermocouples have been tried without much success. Infrared radiometry at the interface between a solid explosive and a transparent salt window showed considerable promise (22), and improved detectors and calibration sources may soon make this technique quantitative (23). Similar pyrometric and radiometric techniques may also be applicable. Without these time resolved temperature measurements, little modeling progress can be made. 
In addition to the temperature measurements, experiments must be designed to determine which physical processes created the hot spots and the residual shock heating so that they can be modeled in sufficient detail. Several hot spot formation mechanisms for impact ignition and shock initiation, such as viscous void collapse (24) and heating beyond the melting point in shear bands (25), depend on the assumption that the solid explosive has an extremely high viscosity in and behind the shock wave front. Viscosity measurements in shocked organic materials are therefore necessary to determine whether these proposed mechanisms are realistic. Since viscosity increases rapidly with pressure and decreases rapidly with temperature, and shock waves have both, only shock compression experiments designed to measure viscosity can answer this question. Similarly, changes in frequency of the vibrations of the solid explosive molecule with increased pressure and temperature must be measured, because these changes will affect the heat capacity and thus the temperature of the shocked solid. Studies of explosives in diamond anvil cells (DAC) are very helpful in determining changes in physical properties with high pressure and high temperature, because shock-like conditions can be obtained statically and maintained while experiments are performed. High pressure deflagration rate measurements in DAC's are particularly important to reactive flow modeling (26).

In the area of modeling detonation waves, laser interferometric techniques have been extended into the nanosecond time resolution regime (27). Average particle velocity profiles of the interfaces between detonating solid explosives and transparent materials have been obtained (28). Embedded particle velocity gauges as thin 25 microns have yielded particle velocity flow histories in detonating solid explosives with approximately 4 nanosecond resolution (4). Measurements of the sound velocity in selfsustaining and overdriven detonation waves has resulted in improved reaction product equations of state in the region of the C-J state (29). Resurrection of the fast techniques developed by Hayes and others, such as the reaction zone conductivity probe (30) and the embedded foil gauge (31), with modern diagnostics could be very useful.

The Ignition and Growth model has been normalized to such data (32-35). Failure diameter, detonation wave curvature, corner turning, and other $2 \mathrm{D}$ and $3 \mathrm{D}$ hydrodynamic effects can be modeled. Thus accurate reactive flow model descriptions of $2 \mathrm{D}$ and 3D detonation waves have been developed. -Since most explosive formulations are mixtures of various particle sizes, have binders and sometimes plasticizers added, and are pressed or cast to certain desnsity ranges, reactive flow models which average over these properties work extremely well. To study the effects of particle size, initial density, and initial temperature changes on detonation wave propagation, reparameterization of phenomenological models like Ignition and Growth or JTF is needed. More importantly, the detonation wave front is known to have a complex, 3D structure consisting of interacting Mach stem interactions. This structure has been observed directly in gaseous and liquid explosives and indirectly in solid explosives (36). Optical camera techniques are approaching the spatial and time resolutions to directly observe the detonation wave front in solids (37). Modeling this complex detonation wave front is a requirement of the next generation of mesoscale, predictive reactive flow models based on realistic Arrhenius kinetics.

\section{SUMMARY}

The next generation of multidimensional reactive flow models of shock initiation and detonation of solid explosives are being developed for the large, fast, teraflop computers currently under construction. These models will based on: mesoscale descriptions of the grains, binders, and voids present in pressed and cast solid explosives; improved equations of state; and Arrhenius chemical kinetic decomposition mechanisms. The models will address problems that current models can not, such as the three-dimensional wave front structure of detonation and the effects of particle size, initial porosity, and initial temperature on impact ignition and shock initiation.

For these models to really flourish, a great deal of nanosecond or faster time resolved experimental data must be obtained. The temperature fields of shocked compressed solid explosives must be mapped out very accurately. The viscosity exhibited by shock compressed solid explosives must be measured. Imaginative experimentation is needed to isolate ignition mechanisms and determine which ones dominate. Species concentrations of the explosive, intermediate products, and final stable reaction products need to be measured and nonequilibrium excitation effects understood to build chemical kinetic decomposition pathways for the reaction zones of solid explosives. 


\section{ACKNOWLEDGMENTS}

The author would like to thank Jerry Forbes, Paul Urtiew, David Funk, Riad Manaa, Steven Chidester, and Melvin Baer for many helpful discussions. This work was performed under the auspices of the U.S. Department of Energy by Lawrence Livermore National Laboratory (contract no.W-7405-ENG-48).

\section{REFERENCES}

1. Tarver, C. M., Hallquist, J., and Erickson, L. M., Eighth Symposium (International) on Detonation, Naval Surface Weapons Center NSWC MP86-194, Albuquerque, NM, 1985, pp. 951-961.

2. Johnson, J. N., Tang, P. K., and Forest, C. A., J. Appl. Phys. 57, 4323 - 4334 (1985).

3. Urtiew, P. A., Erickson, L. M., Hayes, B., and Parker, N. L., Combustion, Explosion and Shock Waves 22, 597 - 614 (1986).

4. Hayes, B. and Tarver, C. M. Seventh Symposium (International) on Detonation, Naval Surface Weapons Center NSWC MP82-334, Annapolis, MD, 1981, pp. 1029 - 1039.

5. Breithaupt, R. D. and Tarver, C. M., SPIE Vol. 1346, 1990 , pp. $96-102$.

6. Green, L. G., Tarver, C. M., and Erskine, D. J., Ninth Symposium (International) on Detonation, Office of the Chief of Naval Research OCNR 113291-7, Portland, OR, 1989, p.670 - 682.

7. Bowden, F. P. and Yoffe, A. D., Initiation and Growth of Explosion in Liquids and Solids, Cambridge Press, MA, 1985.

8. Strehlow, R. A., Fundamentals of Combustion, International Textbook Company, Scranton, PA, 1968.

9. Massoni, J., Suarel, R. Baudin, G., and Demol, G., Phys. Fluids 11, 710 - 736 (1999).

10. Cochran, S. G. and Tarver, C. M., in Shock Waves in Condensed Matter-1983, J. R. Asay, R. A. Graham, and G. K. Straub, eds., Elsevier Science Publishers B.V., 1984, pp. 593 - 596.

11. Yoo, C. S and Holmes, N C. in Shock Compression of Condensed Matter-1993, S. C. Schmidt, J. W. Shaner, G. A. Samara, and M. Ross, eds., AIP Press, New York, 1994,pp. 1567 - 1570.

12. Baer, M. R., Kipp, M. E., and van Swol, F. Eleventh International Detonation Symposium, Office of Naval Research, Aspen, CO, 1998, in press.

13. Tarver, C. M., Chidester, S. K. and Nichols, A. L., J. Phys. Chem. 100, $5794-5799$ (1996).

14. Tarver, C. M. and Nichols, $\Lambda$. L., Eleventh International Detonation Symposium, Office of Naval Research, Aspen, CO, 1998, in press.

15. Fried, L. E., Souers, P. C., and Howard, W. M., Eleventh International Detonation Symposium, Office of Naval Research, Aspen, CO, 1998, in press.

16. Ree, F. H., van thiel, M., and Viecelli, J., Eleventh International Detonation Symposium, Office of Naval Research, Aspen, CO, 1998, in press.

17. Tarver, C. M., Combust. Flame 46, 111 - 133 (1982).

18. Gamezo, V. N., Desbordes, D., and Oran, E. S. Shock Waves 9, 11 - 17 (1999).

19. Deak, J. C., Iwaki, L. K., and Dlott, D. D., J. Phys. Chem. A 103, 971 - 979 (1999).
20. Gruzdkov, Y. A. and Gupta, Y. M., in Shock Waves in Condensed Matter-1997, S. C. Schmidt, D. P. Dandekar, and J. W. Forbes, eds., AIP Press, 1998 , pp. $813-818$

21. Yoo. C. S., Holmes, N. C., and Souers, P. C., in Shock Compression of Condensed Matter-1995, S. C. Schmidt and W. C. Tao, eds., AIP Press, New York, 1996, pp.913 - 916.

22. Von Holle, W. G. and Tarver, C. M. Seventh Symposium (International) on Detonation, Naval Surface Weapons Center NSWC MP82-334, Annapolis, MD, 1981, pp. $993-1003$

23. Funk, D. J., Los Alamos National Laboratory, private communication, 1999.

24. Khasainov, B. A., Borisov, A. A., Ermolaev, B S., and Korotkov, Seventh Symposium (International) on Detonation, Naval Surface Weapons Center NSWC MP82-334, Annapolis, MD, 1981 , pp. $435-447$

25. Frey, R. B., Seventh Symposium (International) on Detonation, Naval Surface Weapons Center NSWC MP82-334, Annapolis, MD, 1981, pp. $36-$ 42 .

26. Foltz, M. F., Propellants, Explosives, Pyrotechnics 18, 210 - 216 (1993).

27. Sheffield, S. A., Bloomquist, D. L., and Tarver, C. M., J. Chem. Phys. 80, 3831 - 3844 (1984).

28. Gustavsen, R. L., Sheffield, S. A., and Alcon, R R., Eleventh International Detonation Symposium, Office of Naval research, Aspen, CO, 1998, in press.

29. Fritz, J. N., Hixson, R. S., Shaw, M. S., Morris, C. E, and McQueen, R. G., J. Appl. Phys. 80, 6129$6138(1996)$

30. Hayes, B., Fourth Symposium (International) on Detonation, Office of Naval Research ACR-126, White Oak, MD, 1965, pp. 595 - 601.

31. Hayes, B. Rev. Sci. Instruments 52, $88-97$ (1981).

32. Tarver, C. M., Breithaupt, R. D., and Kury, J. W., J. Appl. Phys. 81, 7193 - 7202 (1997).

33. Tarver, C. M., Kury, J. W., and Breithaupt, R. D. J. Appl. Phys. 82, 3771 - 3782 (1997).

34. Kury, J. W., Breithaupt, R. D., and Tarver, C. M. "Detonation Waves in Trinitrotoluene," to appear in Shock Waves, 1999.

35. Breithaupt, R. D., Kury, J. W., and Tarver, C. M., "Detonation Waves in Cyclotetramethylenetetranitraamine (HMX)," to appear in J. Appl. Phys., 1999.

36. Fickett, W. and Davis, W. C., Detonation, University of California Press, Berkeley, 1979

37. Roeske, F., Lawrence Livermore National Laboratory, private communication, 1999. 